\title{
Severe Presentation of Necrotizing Ulcerative Periodontitis in a Nigerian HIV-Positive Patient: A Case Report
}

\author{
Kehinde Adesola Umeizudike ${ }^{a} \quad$ Kofoworola Olaide Savage ${ }^{b}$

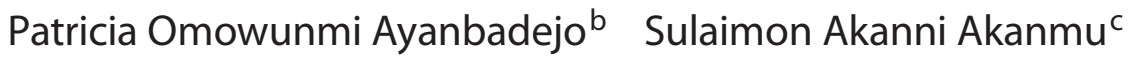 \\ ${ }^{a}$ Department of Preventive Dentistry, Lagos University Teaching Hospital, ${ }^{b}$ Faculty of Dental Sciences and \\ 'Department of Hematology and Blood Transfusion, College of Medicine, University of Lagos, Lagos, Nigeria
}

\section{Key Words}

Necrotizing ulcerative periodontitis $\cdot$ HIV infection $\cdot C D 4$

count $\cdot$ Viral load $\cdot$ Sequestrum

\begin{abstract}
Objective: To report a case of severe necrotizing ulcerative periodontitis (NUP) with a rarely associated sequestrum formation in a Nigerian HIV-positive patient. Clinical Presentation and Intervention: A 47-year-old HIV-positive male patient with no history of previous dental visits presented with a severe toothache in his lower jaw of 4 weeks' duration, which had affected his ability to chew properly. Clinical examination revealed marked gingival inflammation, moderate gingival recession and mobility of some of his lower anterior teeth: 31, 32, and 33. There was also a sequestrum present associated with the affected teeth. His CD4 cell count was 226 cells $/ \mathrm{mm}^{3}$. His viral load was very high $(360,082$ copies $/ \mathrm{ml}$ ). The intervention included thorough debridement of the necrotic lesion and sequestrectomy. The patient responded well to treatment after 1 week of follow-up. Unfortunately, the CD4 count was not assessed further because the patient was lost to follow-up. Conclusion: This case showed that a high CD4 cell count does not necessarily prevent the occurrence of NUP in HIV-positive patients. Intervention might have enhanced a rapid positive response to the treatment within a short time.
\end{abstract}

Copyright $\odot 2011$ S. Karger AG, Basel

\section{KARGER}

Fax +4161306 1234

E-Mail karger@karger.ch

www.karger.com (c) 2011 S. Karger AG, Basel

1011-7571/11/0204-0374\$38.00/0

Accessible online at:

www.karger.com/mpp

\section{Introduction}

Necrotizing ulcerative periodontitis (NUP) is among the earliest oral lesions described in HIV infection and was classified as such among the necrotizing periodontal diseases at the International Workshop organized by the American Academy of Periodontology held in 1999 [1]. Although NUP is the most serious form of periodontal disease associated with HIV, it is still relatively rare with a generally low prevalence of less than 5\% [2]. According to the presumptive criteria of the European Community Clearing House, NUP is defined as periodontitis characterized by soft tissue loss as a result of ulceration or necrosis; severe NUP shows extensive bone loss.

Severe pain is a distinguishing feature and the main reason why patients seek dental treatment. This painful lesion may affect the quality of life and mastication resulting in significant and rapid weight loss. The lesions may occur anywhere in the dental arches but are usually localized. The number of sites affected by papillary destruction has been shown to be significantly determined by tobacco usage [3].

NUP is a marker of severe immunosuppression; however, not all patients who are severely immunosuppressed will present with NUP. Glick et al. [4] reported a strong correlation between NUP and CD 4 cell counts of $<200$ cells $/ \mathrm{mm}^{3}$. Equally, patients with higher CD4 counts of

Dr. Kehinde Adesola Umeizudike

Department of Preventive Dentistry, Faculty of Dental Sciences

College of Medicine, University of Lagos

P.M.B. 12003, Lagos (Nigeria)

Tel. +234805545 1018, E-Mail kumeiz09@gmail.com 


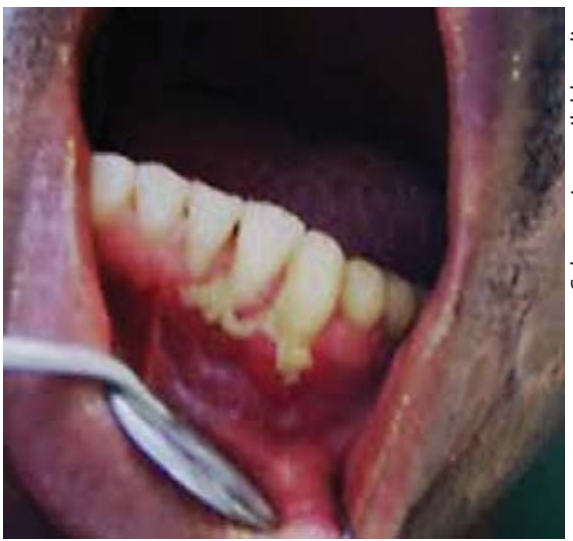

Fig. 1. NUP lesion with associated sequestrum on the inflamed attached gingiva (teeth 31-33) in the lower jaw.

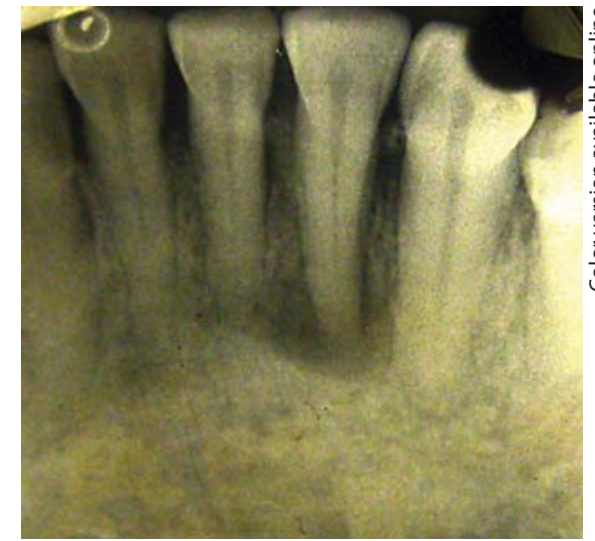

Fig. 2. Periapical radiograph showing marked bone loss extending to the apex of tooth 33 .

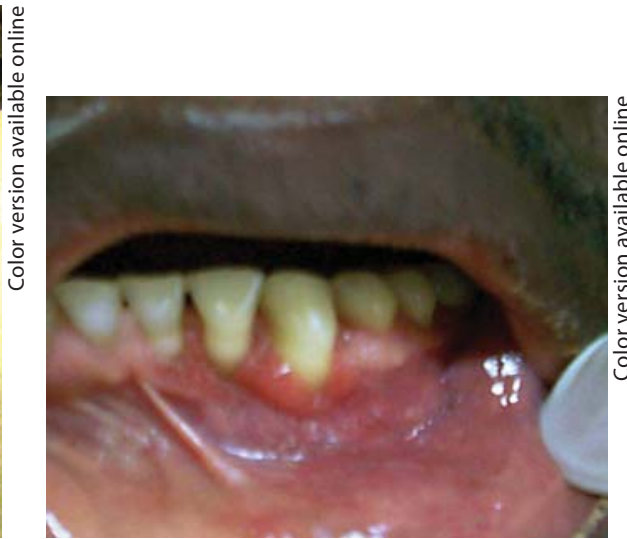

Fig. 3. Postoperative view 1 week following debridement.
$>200$ cells $/ \mathrm{mm}^{3}$ may present with NUP, thereby implying that a combination of other factors may play a role in its pathogenesis. Smoking, subgingival Candida species, poor oral hygiene and high viral loads have been identified as important risk factors in the development of NUP lesions $[3,5]$. The prevalence of NUP has been reported in some studies [6] on HIV-positive patients in Nigeria, but very few have reported its relationship to the CD4 cell count, the association with a sequestrum, or the treatment response of the lesion. We report a rare case from Nigeria, in Sub-Saharan Africa.

\section{Case Report}

A 47-year-old HIV-positive male patient seen at the HIV outpatient clinic presented with a severe toothache in his lower jaw of 4 weeks' duration. The patient described the pain as deep-seated within his jaw which disturbed his mastication. He also complained of occasional spontaneous bleeding from the gingiva of his lower jaw. The patient had been diagnosed with HIV infection a year previously, but was yet to commence antiretroviral therapy until recently when he re-presented with anorexia, progressive weight loss and cough. He also had a healed scar on the left side of his face from a previous herpes zoster infection. He had smoked heavily for about 4 years and claimed to have stopped the habit few months prior to the time of presentation.

Clinical examination revealed a left facial scar from a herpes zoster infection, marked halitosis and a necrotic lesion on the gingiva involving the marginal and interdental papillae of teeth 31 , 32 and 33. There was gingival recession on the labial surfaces of the affected teeth, being most marked on tooth 33, and a periodontal pocket depth of $5 \mathrm{~mm}$. In addition, there was a sequestrum associated with teeth 31, 32 and 33 measuring $20 \mathrm{~mm}$ in width mesiodistally and the affected teeth were mobile (fig. 1).
The oral hygiene was fair (index score of 1.5) with moderate plaque and calculus deposits around the affected teeth.

A periapical radiograph showed marked alveolar bone loss around teeth 32 and 33, which extended to the apical region of tooth 33 (fig. 2). Based on the clinical and radiographic findings, a diagnosis of NUP complicated by sequestrum formation was made. The patient had a CD4 cell count of 226 cells $/ \mathrm{mm}^{3}$ and a viral load of 360,082 copies/ml and CDC clinical stage B2/WHO stage 3 . He was commenced on highly active antiretroviral therapy.

The NUP lesion was thoroughly debrided under local anesthesia and irrigated using $0.2 \%$ chlorhexidine gluconate mouth rinse. Sequestrectomy was performed and a therapeutic regimen was commenced, consisting of systemic metronidazole $400 \mathrm{mg}$ every $8 \mathrm{~h}$, erythromycin $500 \mathrm{mg}$ every $6 \mathrm{~h}$ for 7 days, and local rinses with $0.2 \%$ chlorhexidine. Follow-up of the patient after 1 week of treatment revealed alleviation of the severe pain and initial resolution of the lesion, evidenced by reduced gingival inflammation (fig. 3). However, this patient did not return for his 1-month recall visit and was subsequently lost to follow-up.

\section{Discussion}

This case report demonstrates the characteristic features of NUP that have been reported previously in Nigeria [6] without documentation except treatment outcome.

However, another important finding was the sequestrum formation, which is a rare presentation in NUP lesions reported in Nigeria. Equally important, Riley et al. [7] identified only 2 cases of NUP among 200 HIV-positive patients, and none was found to have sequestra. Generally, there is a rapid progression of soft tissue necrosis 
into the underlying deeper tissues resulting in deep interdental craters, as noted in this case as well as in the cases reported by Riley et al. [7]. Frequently, such defects are located in the molar or premolar region. In this case, the anterior segment of the mandible was affected rather than the posterior region.

Low CD 4 cell counts $\left(<200\right.$ cells $\left./ \mathrm{mm}^{3}\right)$ have been linked to the occurrence of HIV/NUP [4, 8], but in our case, the CD 4 cell count was above 200 cells $/ \mathrm{mm}^{3}(226$ cells $/ \mathrm{mm}^{3}$ ). However, Riley et al. [7] did not find a direct relationship between the presentation of the periodontal disease and the attendant HIV. The probable explanation for the difference between these studies and ours is that other associated risk factors were involved in the development of the lesion. Firstly, our patient had a very high viral load of 360,082 copies $/ \mathrm{ml}$, which has been linked to NUP [9]. However, other predisposing/contributing factors were associated with the NUP cases in the study of Jiménez et al. [10] including malnutrition, acute herpetic gingivostomatitis and poor oral hygiene. Secondly, it was interesting to note that none of the NUP cases in that particular study had HIV or AIDS.

Our patient was also a heavy smoker, although he claimed to have stopped a few months prior to the clinical examination. Cigarette smoking has been shown to be a contributing factor in the progression of periodontitis [3]. Nicotine metabolites concentrate in the periodontium causing impairment of the functional activity of the polymorphs and macrophages.

The management strategies for HIV-associated NUP lesions [11] include debridement of the lesions to remove slough, necrotic hard and soft tissues, as was done in this case. Regular follow-up visits are recommended at 3 -monthly intervals to monitor these lesions which are to be treated promptly in case of any recurrence. The patient's rapid and positive response to the intervention within 1 week could be attributed to several factors: use of systemic metronidazole, which has been reported to be effective in reducing pain and promoting rapid healing of NUP lesions [12], and highly active antiretroviral therapy, which has been shown to reduce the prevalence of NUP lesions in a group of Spanish patients [13].

The symptoms of pain were significantly reduced. This is similar to the treatment response documented by Glick et al. [4] in NUP patients in whom alleviation of pain occurred within $36 \mathrm{~h}$ and initial resolution was noted within 5 days of treatment. However, the patient could not be reexamined beyond 1 week and the CD 4 cell count was not assessed further as he was lost to follow-up.

\section{Conclusion}

This case report showed that HIV-positive patients with relatively high CD 4 cell counts of $>200$ cells $/ \mathrm{mm}^{3}$ may present with severe NUP lesions which may be associated with sequestrum formation. A high viral load and smoking may be associated risk factors which should also be considered by the treating physician referring such patients to the dentist for early intervention to reduce morbidity and improve the patient's overall quality of life. The lesion could respond positively to therapy within a short interval of time.

\section{References}

1 Armitage GC: Development of a classification system for periodontal diseases and conditions. Ann Periodontol 1999;4:1-6.

2 Lamster I, Grbic J, Fine J, Bucklan R, Mitchell-Lewis D, Phelan J, Zambon J: A critical review of periodontal disease as a manifestation of HIV infection; in Greenspan JS, Greenspan D (eds): Oral Manifestations of HIV Infection. Chicago, Quintessence Publishing Company, 1995, pp 247-256.

- 3 Swango PA, Kleinman DV, Konzelman JL: HIV and periodontal health. A study of military personnel with HIV. J Am Dent Assoc 1991;122:49-54.

-4 Glick M, Muzyka BC, Salkin LM, Lurie D: Necrotizing ulcerative periodontitis: a marker for immune deterioration and a predictor for the diagnosis of AIDS. J Periodontol 1994;65:393-397.
5 Lamster IB, Grbic JT, Mitchell-Lewis DA, Begg MD, Mitchell A: New concepts regarding the pathogenesis of periodontal disease in HIV infection. Ann Periodontol 1998;3: 62-75.

6 Taiwo OO, Okeke EN, Jalo PH, Danfillo IS: Oral manifestation of HIV/AIDS in Plateau state indigenes, Nigeria. West Afr J Med 2006;25:32-37.

7 Riley C, London JP, Burmeister JA: Periodontal health in $200 \mathrm{HIV}$-positive patients. J Oral Pathol Med 1992;21:124-127.

$\checkmark 8$ Han Y, Liu HW: Progress on study on oral lesions in patients with AIDS. Beijing Da Xue Xue Bao 2010;42:117-121.

-9 Baqui A, Meiller T, Jabra-Rizk M, Zhang M, Kelley J, Falkler W: Association of HIV viral load with oral diseases. Oral Dis 1999;5:294298.
10 Jiménez LM, Duque FL, Baer PN, Jimenez SB: Necrotizing ulcerative periodontal diseases in children and young adults in Medellín, Colombia, 1965-2000. J Int Acad Periodontol 2005;7:55-63.

11 Grassi M, Williams CA, Winkler JR, Murray PA: Management of HIV-associated periodontal diseases; in Robertson PB, Greenspan JS (eds): Perspectives on Oral Manifestations of AIDS. Littleton, PSG Publishing Co, Inc, 1988, pp 119-130.

12 Scully C, Porter SR, Luker J: An ABC of oral health care in patients with HIV infection. Br Dent J 1991;170:149-150.

13 Robinson PG, Adegboye A, Rowland RW, Yeung S, Johnson NW: Periodontal diseases and HIV infection. Oral Dis 2002;144-150. 